University of Wollongong

Research Online

Faculty of Engineering and Information

Faculty of Engineering and Information

Sciences - Papers: Part A

Sciences

$1-1-2012$

The benefits of introducing electronic health records in residential aged

care facilities: A multiple case study

Yiting Zhang

University of Wollongong, yz709@uowmail.edu.au

Ping Yu

University of Wollongong, ping@uow.edu.au

Jun Shen

University of Wollongong, jshen@uow.edu.au

Follow this and additional works at: https://ro.uow.edu.au/eispapers

Part of the Engineering Commons, and the Science and Technology Studies Commons

Research Online is the open access institutional repository for the University of Wollongong. For further information contact the UOW Library: research-pubs@uow.edu.au 


\title{
The benefits of introducing electronic health records in residential aged care facilities: A multiple case study
}

\begin{abstract}
Purpose: Information and communications technology solutions have been introduced into the residential aged care system in order to improve the effectiveness and efficiency of aged care, however to date, the actual benefits have not been systematically analysed. The aim of this study was to identify the benefits of electronic health records (EHR) in residential aged care services and to examine how the benefits have been achieved. Method: A qualitative interview study was conducted in nine residential aged care facilities (RACFs) belonging to three organisations in the Australian Capital Territory (ACT), New South Wales (NSW) and Queensland, Australia. A longitudinal investigation after the implementation of the aged care EHR systems was conducted at two data points: January 2009 to December 2009 and December 2010 to February 2011. Semi-structured interviews were conducted with 110 care staff members selected through theoretical sampling, representing all levels of care staff who worked in those facilities. Results: Three categories of benefits were perceived by the care staff members according to who gain the benefits: the benefits to individual care staff members, to residents and to the RACFs. The benefits to individual care staff members include an improvement of documentation efficiency, information and knowledge growth as well as empowering the staff; the benefits to residents are an improvement in the quality of individual residents' health records, the higher quality of care and smoother communication between the residents and aged care staff; the RACFs gain an increased ability to manage information and acquire funding, an increase in their ability to control the care quality and improvements in the working environment and educational benefits. Three factors leading to these benefits were examined: the nature of the aged care EHR systems in comparison with paper-based records; the way the systems were used by the staff and one benefit that could lead to another. Conclusions: In this study, EHR systems were perceived to have substantial benefits for care staff, residents and the aged care organisations introducing the systems. The benefits were derived from the nature of the aged care EHR systems, staff members' continuous use of the systems, and one benefit led to the other.
\end{abstract}

\section{Keywords}

health, records, residential, aged, care, facilities, multiple, case, study, introducing, benefits, electronic

\section{Disciplines}

Engineering | Science and Technology Studies

\section{Publication Details}

Zhang, Y., Yu, P. \& Shen, J. (2012). The benefits of introducing electronic health records in residential aged care facilities: A multiple case study. International Journal of Medical Informatics, 81 (10), 690-704. 


\section{Title page}

Title of the manuscript: The benefits of introducing electronic health records in residential aged care facilities: A multiple case study

Authors of the manuscript: Yiting Zhang ${ }^{\mathrm{a}}$, Ping $\mathrm{Yu}^{\mathrm{a}}$, PhD, Jun Shen ${ }^{\mathrm{a}}, \mathrm{PhD}$

Affiliation of the authors: ${ }^{a}$ School of Information Systems and Technology, University of Wollongong, Wollongong, 2522, NSW, Australia

Corresponding author: Ping Yu, PhD, University of Wollongong, Wollongong, 2522, NSW, Australia, Tel.: +61242215412, Fax: +61242214045, E-mail: ping@uow.edu.au

Key words: Benefits; Electronic health records (EHR); Electronic nursing documentation; Interview; Nursing home; Residential aged care; Qualitative study.

\section{Citation of this paper:}

Zhang YT, Yu P, Shen J (2012) The benefits of introducing electronic health records in residential aged care facilities: A multiple case study. International Journal of Medical Informatics 81(10):690-704. 


\begin{abstract}
Purpose: Information and communications technology solutions have been introduced into the residential aged care system in order to improve the effectiveness and efficiency of aged care, however to date, the actual benefits have not been systematically analysed. The aim of this study was to identify the benefits of electronic health records (EHR) in residential aged care services and to examine how the benefits have been achieved.
\end{abstract}

Method: A qualitative interview study was conducted in nine residential aged care facilities (RACFs) belonging to three organisations in the Australian Capital Territory (ACT), New South Wales (NSW) and Queensland, Australia. A longitudinal investigation after the implementation of the aged care EHR systems was conducted at two data points: January 2009 to December 2009 and December 2010 to February 2011. Semi-structured interviews were conducted with 110 care staff members selected through theoretical sampling, representing all levels of care staff who worked in those facilities.

Results: Three categories of benefits were perceived by the care staff members according to who gain the benefits: the benefits to individual care staff members, to residents and to the RACFs. The benefits to individual care staff members include an improvement of documentation efficiency, information and knowledge growth as well as empowering the staff; the benefits to residents are an improvement in the quality of individual residents' health records, the higher quality of care and smoother communication between the residents and aged care staff; the RACFs gain an increased ability to manage information and acquire funding, an increase in their ability to control the care quality and improvements in the working environment and educational benefits. Three factors leading to these benefits were examined: the nature of the aged care EHR systems in comparison with paper-based records; the way the systems were used by the staff and one benefit that could lead to another.

Conclusions: In this study, EHR systems were perceived to have substantial benefits for care staff, residents and the aged care organisations introducing the systems. The benefits were derived from the nature of the aged care EHR systems, staff members' continuous use of the systems, and one benefit led to the other. 


\section{Introduction}

With Australians living longer and the population ageing [1], approximately two million people are currently aged 70 years or older and this figure is set to double within two decades [2]. Increasing longevity is associated with increased occurrence of senility [3], long-term health conditions and complex chronic diseases such as hearing loss and circulatory diseases; and dementia is the commonest among people residing in aged care facilities [4]. In fact, more than half of people aged 65 and over experience some type of disability [4]. The increasing number of older people needing personal assistance for the activities of daily living amplifies the burden on Australia's aged care system.

In addition to the above-mentioned problems associated with an ageing population, there are further challenges posed to the suppliers in the aged care sector. One of the most obvious challenges involves the workforce itself $[2,3,5,6]$. Not only is the number of overall working-age adults in decline, but care staff, in particular, are in short supply and the formal aged care system is facing difficulties in attracting and retaining them. Direct aged care services are labour intensive, however the wages and conditions of care staff are generally less favourable than public health care staff [3,7]. In residential aged care facilities (RACFs), there is a skill shortage among care staff as well as low ratios of registered nurses (RNs) to other care staff $[2,5]$. Furthermore, there is limited after-hour access to and some communication problems with general practitioners [5].

Information technology (IT) systems are often seen as a partial solution for these problems as they are promising to enable the effective delivery of quality aged care. Computerised information systems are expected to reduce work burden and improve the quality of care [3]. Koch and Hägglund [8] suggest that health informatics in aged care is an expanding field of interest where technology is being introduced [9] and evaluated scientifically. The related literature does show a number of identified benefits of these information and communications technology (ICT) solutions. These include ease of access [10-13], improved efficiency $[10,11,14,15]$, improved quality of care [10,14,16-19], improved quality of information (including charts, records and reports) [10-14,20-22], facilitation of management [13,17,20], improved communication [10,17,18,23], cost saving [16,24] and other benefits [16]. Few studies $[10,12,15]$, however, focus on aged care electronic health record (EHR) systems, and none of these systematically evaluates the benefits or how the benefits have been achieved. This study, therefore, aims 
to identify the benefits of EHR systems in residential aged care and examine how the benefits have been achieved.

This study is part of a large project led by the second author between 2008 and 2011 evaluating the success of aged care EHR systems. DeLone and McLean’s information systems (IS) success model provides a comprehensive taxonomy of success variables: system quality, information quality, service quality, use, user satisfaction and net benefits [25]. It has become a source of reference for subsequent studies by various authors [26-32] measuring IS success. The large study also adopted DeLone and McLean’s IS success model as a theoretical framework to measure EHR success. A multi-method approach to evaluation was undertaken: qualitative interview, quantitative questionnaire survey, work activity measurement and auditing paper and EHRs. This article reports the findings about the benefits of EHR gathered from interviewing care staff members. The findings from the other research components have been published elsewhere $[10,12,33,34]$ or are in the process of being written up.

As can be seen from this, there is a real need to understand the perceived benefits of EHR by the end users, i.e. care staff members, and to move from specific observations to a more general theory. Therefore, interpretive research with qualitative interviews is considered the most appropriate starting point, as it provides access to a person's subjective perceptions [35] of the benefits of aged care EHR.

\section{Method}

\subsection{Setting and sampling}

This study was conducted in the Australian Capital Territory (ACT), New South Wales (NSW) and Queensland, Australia. A longitudinal investigation after the implementation of aged care EHR systems was conducted at two data points: January 2009 to December 2009 and December 2010 to February 2011. Nine RACFs under three organisations participated in this research project through a formal research partnership with the university.

The two aged care EHR systems used by the RACFs contained resident demographics, assessments, care plans, progress notes, vital signs, past medical history and current medical diagnosis. One system had a shift hand-over module.

Theoretical sampling [36] was the sampling method for this study. The first theoretical criterion was to select the end users in all types of positions to fully understand their perceptions. Thus the informants 
included all levels of aged care staff: personal care workers (PCWs), endorsed enrolled nurses (EENs) or enrolled nurses (ENs), RNs and managers. In this research, care staff members who worked in the same level as PCWs were also included and grouped into the PCW level. They are assistants in nursing (AINs), care service employees (CSEs) and some staff who function in a variety of roles such as physiotherapists or recreational activity officers (RAOs) in addition to their PCW roles. In addition, team leaders, supervisors and nursing directors were included and grouped into the manager level. The second criterion was to include informants with varying characteristics which could influence their experience with and views of the EHR system. These included the type of aged care facility the staff member worked in (high care or low care), their gender and age, the years they worked in RACFs, previous computer literacy level and their training experience with the EHR system.

In Australia, the qualification for PCWs (AINs/CSEs) can be gained by completing a 12-week study program in aged care at a technical college such as TAFE. Such workers are classified as unregulated care workers, whereas the qualification for an EN/EEN is acquired through an 18-month study program which includes a component of aged care, health issues and medication, also from the TAFE. The RNs are graduates with a Bachelor of Nursing degree from a University.

\subsection{The development of the semi-structured interview questions}

As mentioned, the interview questions were constructed based on the reformulated DeLone and McLean's IS success model [25] to elicit care staff's perception of the performance of each of the six success variables of the EHR systems as well as the implementation process, training, support and system maintenance.

The face validity of the interview guide was validated in a group discussion with a panel of seven key informants, including five experienced nursing managers and two information system managers in an aged care organisation. The guide was then piloted by using it to interview two care staff members at each level of an RACF. The interview guide was refined through the pilot to help the participant feel comfortable up expressing their honest opinions and to improve the understandability and relevance of each question to care staff members.

The interview questions used to capture care staff members' perceptions about benefits of EHR were:

- What are the benefits of EHR? Is there any improvement in residential care using EHR? How? 
- Are there any changes in work practices that are brought about by using the EHR in comparison with the paper-based documentation? How?

For RNs and facility managers, the following additional questions were asked:

- What are the biggest challenges you face in delivering good care to the residents? Is there any help in solving these difficulties using the EHR? How? Please give an example.

- Does the EHR facilitate communication with outside health care providers, such as doctors? How?

- Does the EHR impact on nursing judgment? How?

\subsection{Data collection}

The second author (PY) visited the RACFs at the agreed time with the facility manager. On her visit, she first briefed the manager about the purpose, logistic requirements, procedure and content of the interview. Logistic required informant to be relieved of their care duties in order to be able to participate in the interview and, of course, it was also necessary for an empty room to be provided, one that could be closed for the conduct of interview in order to assure privacy.

After being introduced by the manager to the care team, usually by walking around the work area to meet the care staff members working on the shift, PY made individual personal contact with each participant. First, she would explain to a participant the purpose, nature and procedure of the interview and would assure the person that their participation was completely voluntary and that the information would only be available to the university researchers. Then she would give the participant an information sheet to read. Afterwards she would get written consent from the informant for audio recording of the interview. Then the interview could be started.

Effort was made to include care staff members from all shifts by visiting some facilities during afternoon and night shifts. Questions were also asked about the shift a participant worked. A considerable number of aged care staff members worked in rotational shifts, so the views of the participants from all shifts were captured. 
Data collection at each RACF concluded when 'theoretical saturation' was reached, i.e. when no further new information about a concept or idea discussed in the interview emerged despite repeated questions and the relationships between the concept and the other concepts were well defined [37].

While the research questions were pre-defined, flexible open-ended questions were used in order to explore the emerging issues in the implementation of the aged care EHR systems and to get insight on other issues related to the larger research project.

\subsection{Data processing and analysis}

The audio records were transcribed verbatim into Microsoft Word documents.

As the aim of this study was to understand care staff members' perceptions of the benefits of the aged care EHR systems, analysis was focused on identifying the benefits and how the benefits were achieved.

The unit of analysis was each interview transcript. The interview transcripts were analysed using a qualitative content analysis approach [38]. Each transcript was read carefully thoroughly to gain a sense of the whole. Given the interviewees’ varying ways of describing what they saw as benefits, condensation, a process of shortening while still preserving the core [39], was conducted to code each benefit. A constant comparison [36] and aggregation process [40] led to the abstraction of first-level codes to describe the benefits.

As part of the large study, a quantitative questionnaire survey instrument was developed, which contained questions measuring EHR system quality, information quality, training and support, usage and satisfaction with, and final benefits (PY, manuscript under preparation). The relevant issues asked in the questionnaire survey instrument were the initial reference point for the development of categories of benefits. Further comparison, aggregation, abstraction and classification led to 13 categories of benefits (second-level codes). Thus the original first-level codes became the sub-categories of the 13 categories of benefits. The themes about 'how the benefit was realised' and 'who gained the benefit' were generated by analysing the text in order to understand the relationships and underlying meanings of it [39].

The tentative sub-categories and categories were discussed among three researchers and revised according to consensus. This process of constant comparison, aggregation and classification was iterated repetitively for two months to arrive at set definitions for each sub-category and category of benefits and the themes about how the benefits were realised as well as who gained the benefits. Attempts were made 
to avoid duplication and/or overlap. The following example shows the process of developing the benefits classification system.

The information required for this study was recorded into a Microsoft Excel spreadsheet. Table 1 shows an excerpt of four entries in the spreadsheet. As can be seen in this example, the information recorded in the original analysis table includes the file name of the transcript; the date of the interview; the organisation and the facility the interviewee worked for and the level of care it provided; the interviewee’s demographic information including gender, age group, position, computer literacy level before being introduced to the aged care EHR system (if this information was given in the interview); a direct quotation of what the interviewee said about a particular benefit; the sub-category and category the benefit belongs to. Information about who gained this benefit and how this benefit was realised was also recorded in the analysis table whenever was mentioned by the interviewee.

For example, manager stated that he was ‘able to look up all the information'. Provisionally, we coded this as referring to an advantage of 'access to all information'. An interviewee stated that 'go through things from my office' was the advantage. A PCW called it 'for staff, allied health to be able to access it'. It gradually became obvious that all three of these interviewees were referring to what we then call 'ease of access', so all of the above three statements were placed in the category of 'ease of access', but under different sub-categories of 'access to all the information', 'access at a convenient location' and 'access by all staff'. The original transcripts were recorded in Table 1 as evidence to support the classification. Similarly, when recording the theme about who gained the benefit, several managers stated clearly that the system was useful for them to monitor staff performance, for example, 'So we do use it as a tool for performance management.' One interviewee stated 'you do see what is happening [on the floor]'. We interpreted this as saying it was useful for managers to monitor staff performance and recorded it as such. Linguistic connectors (such as because and for example) were the prompts used to identify how a benefit was realised.

Two types of residential aged care services exist in Australia: high care and low care. The people living in a high care facility suffer from disability and fully depend on care staff members to accomplish their physical activities of daily living. The low level care facility only provides minimal care assistance [33]. 
Table 1 - An excerpt of content analysis of the transcripts

\begin{tabular}{|c|c|c|c|c|c|c|c|c|c|c|c|c|c|c|c|c|}
\hline \multirow[b]{2}{*}{ Entry } & \multirow[b]{2}{*}{$\begin{array}{l}\text { File } \\
\text { Name }\end{array}$} & \multirow[b]{2}{*}{\begin{tabular}{|l} 
Data \\
Collection \\
Time
\end{tabular}} & \multirow[b]{2}{*}{$\begin{array}{l}\text { Org+ } \\
\text { No. }\end{array}$} & \multirow[b]{2}{*}{$\begin{array}{l}\text { Facility } \\
\text { No. }\end{array}$} & \multirow[b]{2}{*}{$\begin{array}{l}\text { Care } \\
\text { Level }\end{array}$} & \multirow[b]{2}{*}{$\begin{array}{l}\text { EHR } \\
\text { System }\end{array}$} & \multirow[b]{2}{*}{ Gender } & \multirow[b]{2}{*}{$\begin{array}{l}\text { Age } \\
\text { Group* }\end{array}$} & \multirow[b]{2}{*}{$\begin{array}{l}\text { Computer } \\
\text { Literacy } \\
\text { Level§ }\end{array}$} & \multirow[b]{2}{*}{ Position } & \multicolumn{6}{|c|}{ Benefits } \\
\hline & & & & & & & & & & & $\begin{array}{l}\text { Whose } \\
\text { gain? }\end{array}$ & $\begin{array}{l}\text { What is it? } \\
\text { (transcript) }\end{array}$ & Sub-category & Category & $\begin{array}{l}\text { How was it achieved? } \\
\text { (transcripts) }\end{array}$ & Reason \\
\hline 153 & 300192 & $12 / 2010$ & 1 & 2 & High & $\mathrm{X}$ & $\mathrm{F}$ & Older & Confident & PCW & All staff & $\begin{array}{l}\text { Facilitated } \\
\text { communication } \\
\text { between team } \\
\text { members }\end{array}$ & $\begin{array}{l}\text { Internal } \\
\text { communication }\end{array}$ & Communication & $\begin{array}{l}\text { But the people that come } \\
\text { on say they've been up } \\
\text { until quarter past six, and } \\
\text { they can sit and look } \\
\text { through that and they can } \\
\text { say, well that's what } \\
\text { happened in the morning. }\end{array}$ & $\begin{array}{l}\text { Awareness } \\
\text { of residents }\end{array}$ \\
\hline 515 & 300151 & 03/2009 & 3 & 8 & High & $\mathrm{Y}$ & $\mathrm{F}$ & Other & Zero & RN & $\begin{array}{l}\text { All staff } \\
\text { and outside } \\
\text { health } \\
\text { providers }\end{array}$ & \begin{tabular}{|l} 
Facilitating \\
communication \\
with external \\
health care \\
providers
\end{tabular} & $\begin{array}{l}\text { External } \\
\text { communication }\end{array}$ & Communication & $\begin{array}{l}\text { Because you have your } \\
\text { information at hand. If they } \\
\text { ask you about anyone you } \\
\text { can get it immediately, } \\
\text { before you'd have to go to } \\
\text { the cupboard and pull it } \\
\text { out files and find where } \\
\text { they are. }\end{array}$ & $\begin{array}{l}\text { Quick data } \\
\text { retrieval }\end{array}$ \\
\hline 325 & 300143 & $12 / 2009$ & 2 & 6 & High & $\mathrm{Y}$ & $\mathrm{F}$ & Other & Basic & RN & Interviewee & $\begin{array}{l}\text { And it [input } \\
\text { data in EHR } \\
\text { system] spent } \\
\text { less time than } \\
\text { handwriting. }\end{array}$ & $\begin{array}{l}\text { Easy and quick } \\
\text { data input }\end{array}$ & $\begin{array}{l}\text { Convenience } \\
\text { and efficiency in } \\
\text { data entry, } \\
\text { distribution, } \\
\text { storage and } \\
\text { retrieval }\end{array}$ & $\begin{array}{l}\text { Because before usually we } \\
\text { didn't have time to hand } \\
\text { write it down, and also we } \\
\text { had to go upstairs and find } \\
\text { the residents folder every } \\
\text { time we would have needed } \\
\text { to document. This is much } \\
\text { more efficient. }\end{array}$ & $\begin{array}{l}\text { Quick data } \\
\text { retrieval } \\
\text { and access } \\
\text { from } \\
\text { anywhere }\end{array}$ \\
\hline
\end{tabular}

Org = Organisation

* Older = Self-identified as an 'older’ member of the care staff; Other = All the other participants.

$\S$ Self-identified computer literacy level before the EHR system was introduced. Zero $=$ Never used computer before; Basic $=$ Limit computer experience and novice; Confident $=$ Computer literate and confident. 
Information about the level of care provided by each RACF was obtained by directly asking the participants.

\subsection{Ethics approval}

Ethics approval was obtained from the University of Wollongong Ethics Committee. Access to an RACF was given by the management of the relevant organisation. Agreement on the date and time of the field investigation was made with the manager of each RACF. The written or oral consent was acquired from each participant before starting interview and recording it.

\section{Results}

Nine RACFs under three aged care organisations participated in the study. They provide either high or both high and low levels of aged care services to the residents. The size of the RACFs ranged from 60 to 152 beds. Six RACFs are located in urban areas, two are located in suburban areas and one is located in rural area. Two commercial EHR systems from two companies were used in these facilities, with seven facilities in two organisations in ACT and NSW using one and two facilities in the third organisation in Queensland using the other. Data was collected from 110 interviewees. Table 2 shows the facility characteristics and the number of different levels of participants in each RACF.

Table 2 - The facility characteristics and the number of different levels of participants in each RACF

\begin{tabular}{|c|c|c|c|c|c|c|c|c|c|}
\hline \multirow{2}{*}{$\begin{array}{c}\text { Organisation } \\
\text { no. }\end{array}$} & \multirow{2}{*}{$\begin{array}{c}\text { Facility } \\
\text { no. }\end{array}$} & \multirow{2}{*}{$\begin{array}{l}\text { Facility } \\
\text { type }\end{array}$} & \multirow{2}{*}{$\begin{array}{l}\text { Facility } \\
\text { bed size }\end{array}$} & \multirow{2}{*}{$\begin{array}{l}\text { Facility } \\
\text { location }\end{array}$} & \multicolumn{4}{|c|}{ Position category of participants } & \multirow{2}{*}{$\begin{array}{c}\text { Total number of } \\
\text { participants }\end{array}$} \\
\hline & & & & & Manager & $\mathbf{R N}$ & EEN/EN & PCW & \\
\hline \multirow{2}{*}{1} & 1 & Mix & 60 & Urban & 1 & 2 & 1 & 8 & 12 \\
\hline & 2 & Mix & 120 & Urban & 2 & 5 & 5 & 14 & 26 \\
\hline \multirow{4}{*}{2} & 3 & Mix & 120 & Suburb & 9 & & & 15 & 24 \\
\hline & 4 & Mix & 152 & Suburb & 2 & & & 4 & 6 \\
\hline & 5 & Mix & 74 & Urban & 9 & & & 2 & 11 \\
\hline & 6 & Mix & 108 & Urban & 2 & 3 & 1 & 2 & 8 \\
\hline \multirow{3}{*}{3} & 7 & High care & 62 & Urban & 1 & 1 & 1 & 5 & 8 \\
\hline & 8 & Mix & 90 & Rural & 2 & 2 & 1 & 6 & 11 \\
\hline & 9 & Mix & 101 & Urban & & 1 & & 3 & 4 \\
\hline \multicolumn{5}{|c|}{ Total number of participants } & 28 & 14 & 9 & 59 & 110 \\
\hline
\end{tabular}

Mix: both high care and low care services 
527 entries of benefits were derived from the transcripts. Figure 1 shows the 10 most frequently mentioned benefits. In descending order, they are: Quick data retrieval (mentioned by 58 participants), easy and quick data input (mentioned by 43 participants), ease of access to aged care EHR (mentioned by 39 participants), improving format of records (29 participants), improving content of records (26 participants), facilitating communication with external health care providers (20 participants), more information about the residents (19 participants), staff being motivated to enter data into EHR systems (18 participants), facilitating communication among the staff members (18 participants) and facilitating performance appraisal by the management (16 participants).

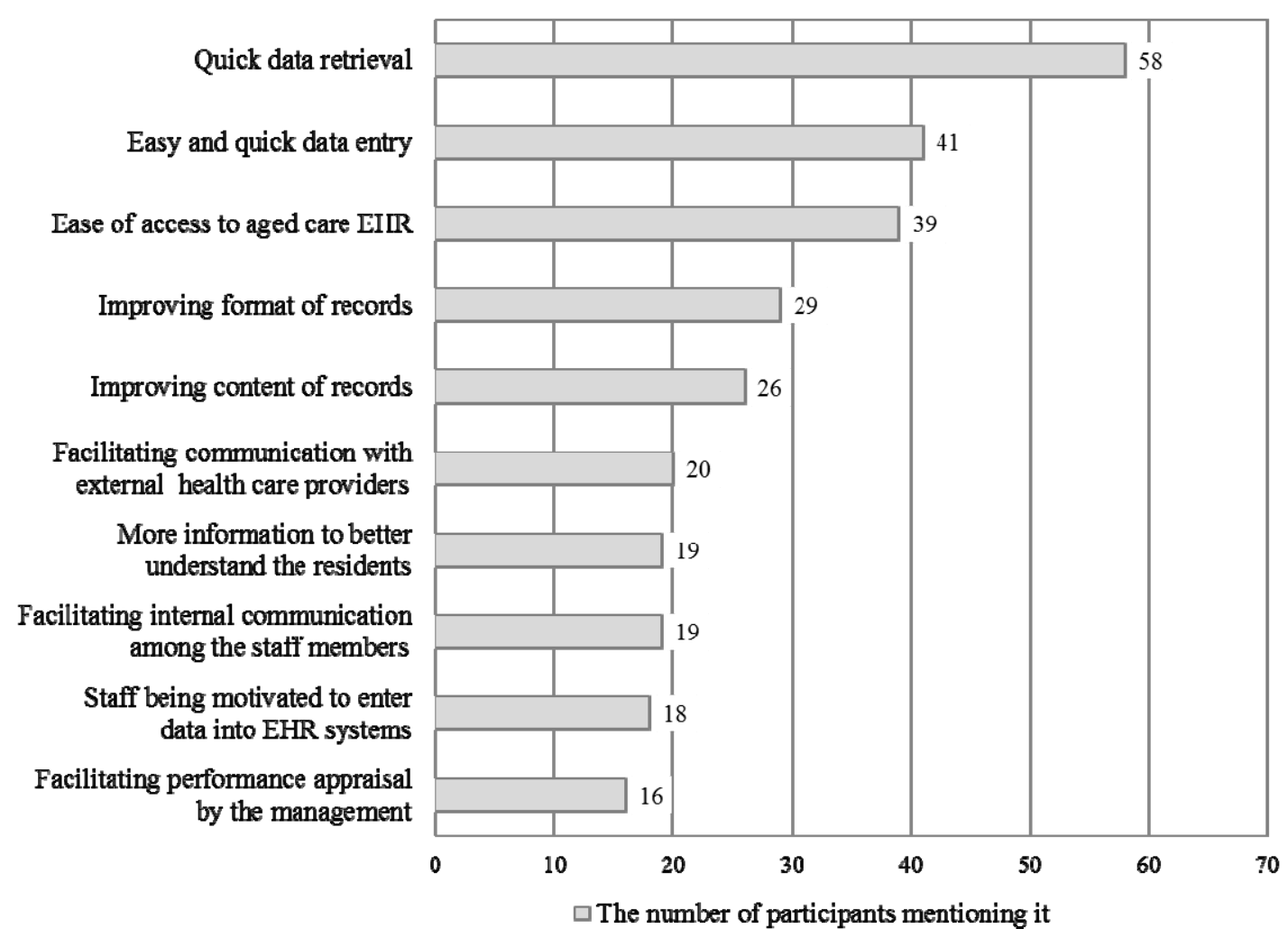

Fig. 1 - Top 10 mentioned sub-categories of the benefits

The benefits were organised into three groups based on who gained the benefits: the aged care staff, the residents and the RACFs and organisations. The key findings about the benefits perceived by the participants are discussed in the following sections. 


\subsection{The perceived benefits to the aged care staff}

Most of the participants reported their satisfaction with the aged care EHR and the process of implementing the system. Good acceptance of the EHR by aged care staff was shown by 305 entries of benefits from 96 (87\% of) participants. The most commonly viewed benefits for individual care staff members are time efficiency, ease of access to the system, and more information to better understand the residents, to assess staff performance and to foster the delivery of better care.

\subsubsection{Convenience and efficiency in data entry, distribution, storage and retrieval}

All levels of care staff members saw a reduction of paperwork and time saving after the system was implemented. There was a total of 154 entries from 89 (81\% of) participants who reported that the EHR system had improved time efficiency in documentation. The explanation staff gave of how the benefit was realised was that they gradually got rid of paper and saved the time which they used to have to spend in writing by hand, searching for and filing documents. One of the RNs who did not even know how to type before the introduction of the aged care EHR told us:

'[The time that documentation takes is] not that long because we are getting very proficient at using the computer...It is quicker.'

The benefits of convenience and efficiency were manifested by easy and quick data input, quick data distribution, convenient data storage and quick data retrieval.

Easy and quick data entry

41 (37\% of) participants reported that entering data into the computer was easier and quicker than writing on paper. This benefit was mentioned 49 times. It was reported that computer worked better for note entry because it stopped hands being tired from writing and messy corrections of handwriting mistakes. It also enabled a simple copy/paste when information needed to be recorded again. Moreover, the care staff could create a new document at the click of a mouse instead of needing to look for blank paper forms. Once a care staff member became familiar with typing and using the electronic system, data entry was very efficient.

'I think the computer is quicker because you can get to delete stuff and you can fix it.'

“...care plans on paper are very time consuming, and the computers make it faster, since when it's written once, you don't need to write it again.” 
'...it's easier for them [the care staff members] to do it [data entry] even if they're only typing with two fingers.'

\section{Quick data distribution}

Another benefit of the EHR systems which was noted was quick data distribution. Because the system was real-time, it allowed care staff members to access records instantaneously through various terminals. This was mentioned by 10 (9\% of) participants 12 times. The information could be read immediately by others on all terminals and critical information about a resident could be printed out in multiple copies much quicker than by filling out paper forms. The system enabled managers to publish announcements. It also allowed sharing a resident's information, such as care plans at all levels of the organisation. A manager stated that:

'I just need to enter it into the computer and then that information is there for the staff to see...So it saves a lot of time.'

\section{Convenient data storage}

11 entries from 9 (8\% of) participants reported this convenience. The reasons mentioned include all the records were in digital form and stored in servers with backup. This ensured the records were less likely to be lost than paper records if the organisation managed the system appropriately. Unlike hand-written paper records, electronic ones do not deteriorate over time. Also, saved records could not be edited or deleted by unauthorised persons, thus preventing actions which could breach the law.

\section{Quick data retrieval}

Quick data retrieval was another well-recognised benefit of EHR systems. 58 (53\% of) participants saw the benefit after the system had been implemented. They found it was quicker and easier to find both upto-date as well as historical data without walking to the store room and flicking through folders. The user interface of the system was well designed to show the retrieved information in a logical order, as one care worker described:

‘...being able to scroll through and the way the notes are broken up into different categories where you can select whatever it is you are looking for and be done fairly quickly.' 
The system also provided a useful function that facilitated care staff tracking through the progress notes for a resident to get a holistic view of the person's behavioural changes over time, making it easy to identify potential triggers for the change or any issues which might need to be followed up.

\subsubsection{Ease of access to aged care EHR}

Ease of access to the EHR was one of the frequently reported benefits. There were 53 entries from 39 (35\% of) participants who reported it. The participants stated that they were able to access all the information they needed, the system was running 24 hours a day so that they could access it at any time during their shift. All of the staff were given the authority to log on to the system by using computers in any nurses' station, so the staff on the floor was able to access the information they needed at the nearest nurses' station after logging in. The managers and RNs could access the system, check information and prepare documentation in their offices and did not need to walk out onto the floor to get paper forms. In addition, it was reported that the relevant staff members in the corporate office of the organisation were given the authorisation to access the information of every facility owned by the organisation.

\subsubsection{More information to better understand the residents and the care services, to support peer learning and to facilitate performance appraisal for managers}

It was reported that because of the ease of access, staff felt able to read more information in the EHR than they did in the paper-based record system, and this was perceived to have improved their understanding of residents' care needs. 65 entries from 41 (37\% of) care staff members from all levels of the organisations reported a significant increase in the amount of information they acquired about the residents and the care services. It was also believed that the information had supported peer learning or facilitated staff appraisal by managers.

\section{About the residents}

The staff appeared to get a broader and more holistic view of residents. The convenience of quickly accessing information and finding the details of what was happening to the residents enabled the staff to gain a better understanding of what a resident's need was. A manager said:

‘...sometimes it [the information about residents] wasn't written anywhere [when we used paper records], so they [the care staff members] might say they didn't know. Now there is no excuse for not knowing what's happening.' 
By viewing the photos of a resident in the EHR, a new staff member was able to call a resident by name at their first encounter and start a conversation on a more personal basis. For the residents with the same first name, staff members were able to add information to note that there was a person with a similar name besides the photo so they would not misidentify people.

\section{About the care services}

Care staff members reported that the system enabled them to easily check what care had been delivered by others. As long as a staff member was comfortable using the system, the completeness and accessibility of information would facilitate a better understanding of what was happening on the floor. Care workers were more aware of the updated care plan developed by RNs because soft copies of care plans in a real-time system could be easily accessed at every computer terminal, not like the usual single copy paper-based care plans. Care workers expressed their satisfaction with the easy access to care plans and knowing what to do and why they needed to do it, instead of simply following workflow without thinking.

'...if staff log on to the documentation, look at the care plan that will build them a picture about what they should do with the person.'

'We do care plans so that we can print them out for the staff so they know if a resident needs to be lifted by a hoist or can feed herself, or is on a normal diet.'

\section{Supporting peer learning}

Several interviewees reported the benefits of increasing working knowledge after using the EHR system, because they could learn from each other by reading the records entered by their colleagues. Also, some particular user groups such as managers were given the authority to access the records of other aged care facilities within the same organisation. This allowed these managers to learn how the care or the management for similar cases at another facility was being conducted.

'For instance if I am unsure of how to do the palliative care, I can easily just click a button and find out it has been done for a similar patient at another facility.'

'We're all still learning I feel, we're learning something new every day.' 


\section{Facilitating performance appraisal by the management}

The aged care EHR systems helped managers to monitor staff work performance. Managers had authority to check who created and modified the documents. They were able to check frequently in a timely way whether carers had completed the work as well as the documentation. This was much more convenient than walking on the floor, asking others and shuffling papers. In addition, it helped the managers to identify the learning needs of the staff and to provide more targeted training courses.

'...able to see if something has been identified, has somebody done something about it, if there is a gap and ensure that is corrected.'

'It helps me identify what is needed by the staff.'

\subsection{4. $\quad$ Staff being motivated to enter data into EHR systems}

The easy accessibility of the EHR systems was seen as enabling care staff to enter data into the computer as soon as they finished the task at hand, while the issue was still clear in their mind. This was reported to encourage care staff to enter data more often.

In seven facilities belonging to the three organisations, it was mentioned by 18 (16\% of) participants that the staff members put more effort to input data in the EHR system than they did when writing in a paperbased record system, where there might only be RNs taking the role of documentation.

'My experience is here people make that little bit more effort to document well and regularly. In a paper system it tended to be the RN that documented and not the carers.'

\subsubsection{Empowering care staff}

Most staff who had limited computer skills or did not use computers prior to the introduction of EHR expressed their willingness to use the computer as a part of their job. They improved their computer skills after using the system for several months. Some of the senior-aged care workers gradually gained confidence with using the system, especially for typing, which they saw as a personal achievement. Some felt that their newly acquired computer skills would contribute to their CV and other aspects of their life. Seven (6\% of) participants reported this benefit.

'It's a part of the job and it's good to learn for future references.'

'It's a good learning experience. I feel like I can keep up with the generation a bit with the grandkids.' 
'...the software contributes to making your life easier.'

Some PCWs felt they were more important than before, because they could enter notes in the system and those notes were more likely to be read by other care staff members in an EHR system than in a paperbased record system, where it was the RNs' role to record. What they had contributed was quickly known by the managers and what they had recorded about a change of a resident was helpful for RNs to redesign a care plan. As an RN mentioned:

'get the information from people you can't talk to at the moment - what they think - so it does improve what you want to do because you get the whole picture, not just what's happened on your shift...it does impact on how I deal with a resident.'

Another PCW also expressed her feeling of confidence in delivering care service after the aged care EHR system was utilised:

'So it is really good feedback instead of someone just giving a handover and saying, so and so has been aggressive today. So you can look more into depth of the person that it happened with.'

\subsection{The perceived benefits to the residents}

59 entries of benefits from 37 (34\% of) participants belong to this group. It was reported that the improvement in the quality of residents' records led to the improvement in the quality of care and better communication between staff and residents.

\subsubsection{Improving the quality of care}

Delivering high quality care to the residents is the aim of every care staff member and there were 33 (30\% of) participants who reported that the aged care EHRs could assist them to achieve this goal by facilitating the following actions: facilitating a quick response to residents' care needs, supporting the development of care plans, facilitating quicker and easier care decisions, resident-centred care, better care follow-up and limiting the number of incidents of undesirable behaviour.

Quick response to residents' care needs

The staff members in RACFs were able to respond more quickly to residents' care needs due to up-todate information and significantly improved internal communication. They were also able to communicate with outside health care providers with the timely information and quick responses facilitated by the system. 
'We take photos, we store them in [the EHR system X] on the computer, so we can e-mail off to the doctors and it's a lot quicker response.'

When a new resident came in, initial assessment of the person could be distributed to all of the staff members through the system, so that correct care could be started immediately instead of waiting for the next shift.

'Now correct care can start immediately instead of maybe the next shift. I can get initial assessments out to the staff that are on the floor.'

\section{Supporting the development of care plans}

The interviewees reported that the aged care EHR system made the development of better care plans easier because the information was more accessible. As the quick data retrieval and the compact information was shown on the screen, a care staff member could quickly switch among the notes in an assessment and efficiently combine all the information together to formulate a care plan.

'I can combine notes together and use your high thinking skills in assessment and from your own knowledge of the resident, formulate a plan of care.'

'[It is] very easy [to develop care plans in the aged care EHR system]; because you literally select the resident, and check all forms if you looking for a particular accident or incident at date range; you're looking for a date range, and it's there.'

\section{Quicker and easier care decisions}

Interviews with the RNs and managers revealed that the EHR systems had a definite impact on clinical judgement and decision making because of the easy availability of quality information. Seeing GPs' notes and the assessments of the residents in the system enabled the RNs to think more critically about the care plans. It was easier for nurses to formulate a care plan with the information from both internal and external sources which could be shown compactly on the screen. It was also helpful to be able to notice some behavioural changes by checking historical progress notes quickly and thus be able to change the care plan accordingly and in a timely way. The interviewees reported an improvement in the quality of care decisions when using the system.

'You can see the doctor's notes, the staff's and any assessments. This way you can make judgments a lot more quickly and thoroughly.' 


\section{Resident-centred care}

The timely and complete information in the system helped staff to get a better understanding of the needs of residents. This enabled them to better meet a resident's needs by paying more attention to what would be really helpful to the person.

'...they [the care staff members] know what that person needs. So all they need to do is deliver that need.'

'And I think [the EHR system X] does give you that person centred focus, because you get that holistic view so it is much more person centred than meeting funding needs.'

\section{Better care follow-up}

It was more convenient for a staff member to dig into a resident's record deeply and check the care given to this resident by other staff members. Electronic handover was used in some of the participating facilities to replace a paper handover. The staff who worked in a facility which still kept a paper or oral handover was able to check such information too. The interviewees said that although they preferred oral communication, if they could not get the detailed information they wanted, they would check on the EHR. Staff felt there had been a significant enhancement in care follow-up.

'There's a lot more follow-up with resident care because there's more accessibility of information.'

\section{More time spent with residents}

Because less time was required for documentation, the care staff members felt they were able to spend relatively more time on the floor in the direct delivery of care. They were very happy to have this extra time with the residents.

‘...so you have more time on the floor with the residents. I think it [documentation in the aged care EHR system] is quicker.'

\section{Fewer incidents of undesirable behaviour}

The ease of going through many records in the system than going through paper files was reported. Staff took advantage of this benefit to analyse the common occurrences of certain undesirable individual behaviours in order to understand why they had occurred. They felt that the results of such analysis had enabled them to avoid such triggers and thereby minimise the number of such incidents. 
‘...we can alter something to prevent it happening again. It has individual behaviours and we can go into the files and see if this is a common occurrence and why it is occurring...It's not easy to go through lots and lots of paper.'

\subsubsection{Enabling better communication between care staff and residents}

It was believed that the system was especially helpful for new staff members because they could see the photos of the residents, and thus learn their name easily. In addition to the photos, by using the system to easily access personal information, staff had a better personal understanding of their residents. This helped to connect a care giver to a care recipient. One PCW expressed it in this way:

'It's great because we can look up on the system to find out a little bit about their background, it assists us make a topic of conversation when go in to them.'

\subsection{The perceived benefits to the RACFs}

The benefits to the RACFs were identified as improvement in information management and communication, and the associated benefits of: improving accessibility to funding, facilitating care quality control, improving the work environment, and improved learning experiences for nursing students. 124 entries of benefits from 68 (62\% of) participants identified these benefits.

\subsubsection{Better information management}

Information management was improved in terms of increased accessibility to nursing records; convenience and efficiency in data entry, distribution, storage and retrieval (see section 3.1). An improvement in the quality of nursing records was also noted. One manager expressed his satisfaction with the result of an accreditation report issued by the outside surveyors because it showed a significant improvement in the quality of records.

'Now, in our accreditation report these surveyors talk about [the EHR system X] and how useful it was, and they saw that as a plus to our documentation.'

Another example was that relevant staff members could easily conduct internal audits in the corporate office because they were authorised to access those EHRs belonged to all the branch facilities.

Improved quality of nursing documentation

There were 66 entries from 48 ( $44 \%$ of) participants which reported such benefits. Nursing records are more than the records of care which is planned and given to individual residents [41]. They can be the 
evidence used for quality assurance, legal purposes, health planning, allocation of resources and nursing development and research [42]. The quality of nursing records was improved in two aspects: format and content.

\section{Format}

The data items on the electronic form were laid out in a logical order. Printed text was much easier to read than untidy or even illegible handwriting. The interface for data entry for assessments would pop-up straight away when a user logged in. This provided staff members with quick access to the data entry form.

'Once you go in, it flashes up the focus assessments straight away. You need to be doing this focus assessment and that focus assessment, so you can start doing it.'

As more content could be displayed on one screen, it allowed information in one place for the staff to switch between residents and/or different types of records at the click of a mouse. 13 people reported this benefit. The legibility improved reading speed and encouraged care staff members to read the records, thus improving the usefulness of the records.

'Previously that had been a problem with orientation because the paperwork used to be pages and pages, put in a folder, stashed away and not likely to be read.'

'I see a benefit of it being typed over handwritten as it can be more legible.'

\section{Content}

The records were more accurate, up-to-date and complete than paper records because of the easy accessibility and improved efficiency in data entry, distribution, storage and retrieval. One interviewee reported the photos of the residents were put into the system and shown in a prominent position. This enabled her to avoid the mistake of mixing the records of the residents with similar names.

The interviewees also reported that the records became more concise and there were fewer mistakes in them. The reason could be that they were legible and it was also easier to make corrections on computer than by hand as staff tended to do proof reading before saving the records. More staff chose to delete or simply not enter the information that was not relevant, as well as checking for typos and spelling mistakes, as two PCWs mentioned: 
'...if you write something in and think, no it sounded better this way, you can change it.'

‘...you are typing it up, if you make an error you can correct it. Whereas if you hand write it, it's a different issue.'

\subsubsection{Improving the communication system}

Improvements in both internal and external communication were also seen as benefits of introducing the EHR system. Compared to a paper-based record system, the EHR system was more convenient for staff to exchange clearer information. Expedited communication facilitated much greater collaboration. 37 entries from 33 (30\% of) participants reported the benefit of improved communication. This could be seen in three areas: facilitating internal communication among the staff members, facilitating communication between staff members and residents and facilitating communication with external health care providers. The benefit of improved communication between staff members and residents has already been discussed in the section concerning benefits to the residents, but the other areas of improved communication were also perceived as important.

\section{Facilitating internal communication among the staff members}

19 (17\% of) participants recognised a benefit in this sub-category. The system helped staff to be more aware of what others were doing and why because of the ease of data retrieval. The handover function in the system had already substituted a handover book in some of the participating facilities. The important information was highlighted to draw everyone's attention. Care staff members who went on leave could read the notes and catch up with the events which had happened while they were away. This was reported by 5 interviewees as major benefits.

'If you've had a few days off, it's easier to go and look at what's happened while you're not here.'

'Because we are 24 hours, if we have to write notes we can enter them and someone can come along at any stage of the day and read them. It's communicating with other team members that are working on a different shift.'

\section{Facilitating communication with outside health care providers}

The communication between the staff in aged care facilities and outside health care providers was also facilitated by timely data input and frequent record retrieval. When the providers came into aged care facilities, they could easily be shown all the information they needed in the system and this gave them a 
clear picture of the residents. Staff could take photos of wounds and store them in the system. They could email the health care providers and receive a quick response. This greatly improved communication with outside health care providers. 20 (18\% of) participants recognised this benefit.

'...with their [nurses'] clinical notes as well you can print out a page and shoot it off in an e-mail to a doctor and they will get on a lot quicker than having to wait for them to come back here and attend.'

\subsubsection{Improving access to funding}

The Aged Care Funding Instrument (ACFI) was also integrated into the system. Most of the managers expressed the view that the system assisted the facilities to get funding. The income of some facilities had improved, particularly in the case of high care facilities.

'...with this introduction of ACFI...the income of...facility...is definitely up...When we went into ACFI we had all high care on high money.'

\subsubsection{Facilitating care quality control}

The EHR system facilitated the auditing of internal documents since the records of each facility in an organisation could be easily accessed from the corporate office. The managers acquired the benefits of aged care EHR because it provided complete information, the convenience of tracking the historical records of residents and staff work performance. One manager stated that they easily collected the clinical indicators and reported them at monthly quality meetings in the RACF where he was working. They added graph information in the reports and compared it with the previous records to see trends in the quality of care. Based on the results of the observation, they could control the quality of care by adjusting the management strategies accordingly.

'I'm finding there are a lot more involved observation and report writing going into the [EHR system $\mathrm{X}]$.

'[Person A] uses it for clinical indicators and our clinical indicators are reported to a quality meeting every month and we're also able to graph information and compare it with the previous months or the same month last year so we can develop trends.'

\subsubsection{Better work environment}

The use of the EHR system eliminated the amount of paper documents, which saved all the space which used to be needed for paper files as well as the cost of buying paper and cabinets. The staff working 
environment was also tidier. Interestingly, one interviewee reported that one benefit was to avoid bringing in insects or a fire hazard.

\subsubsection{Educational benefits}

Providing better opportunity to educate practising students about nursing documentation and practice in an RACF was also seen as a benefit by one interviewee. Because of the completeness of information in the system and the high computer literacy of most students, teaching students nursing documentation was easier than before and the students could go into the system to find all the information they needed to learn about issues related to nursing care with little staff direction.

'Opportunities to, like I said, all the information that we need or help out with the students today. Like they wanted to know a little bit about all the resident's conditions and stuff, so I just set them up on my [System Y], and they sat on there for a couple of hours and they really enjoyed it. Say a thing, they were able to find out everything they wanted to know about all the residents as well.'

\subsection{How were the benefits realised}

Various factors contributed to the realisation of the above benefits. The factors were categorised into three interconnected and interrelated groups: the nature of the EHR systems, the way the system was used by the staff and the way that the realisation of one benefit often led to further benefits.

\subsubsection{The nature of the EHR systems in comparison with paper-based records}

This includes the ease of learning and use of the EHR system and customisable nature of the EHR. Regardless of the age group and computer literacy level of the participating care staff, they had all felt to benefit from ease of learning and use of the computer system. As the EHR system was user-friendly and self-explanatory, it did not take long for the trainer to teach and the user to learn. Some interviewees reported they could use it the first time they logged in, without any orientation. As the documents and charts were logical, the staff had no problem understanding and following through. Another aspect of the electronic system was the flexibility for authorised staff to customise the system. This meant that there was autonomy for each organisation to design and update its own forms.

'That has been more of an in-house update, not something that [the EHR vendor] did themselves... [person B] actually designed the form like our shift handovers, and actually put it into [the aged care EHR system]... and we use it to communicate any changes to the managers.' 
The EHRs are more legible than paper-based records because printed text is easier to read. The digital storage media reduced paperwork and the real-time system was Internet based, thus enabling quick data retrieval and transfer.

\subsubsection{The way the system was used by the staff}

These were the benefits which occurred because staff members were more willing to enter data into the EHR systems than writing on paper. They accessed related records to learn how to deliver care from similar cases and tracked the clinical indicators for further studies and care quality control. For example, staff could take photographs of wounds and store them in the system, so that they would be able to email outside health care providers and receive a quicker response. These actions greatly improved communication. With the assistance of the system, the staff also thought more critically, rather than mechanically following the workflow without thinking why they needed to do what they were doing or how they could improve the services they were delivering.

'The strengths are that I can read back on the progress notes to see what's happened to people for the last few days...you hope it's all there and everyone documents as well all the time.'

'It [the aged care EHR system] makes it very easy to be able to use their critical thinking if they use it properly...all the information is there. If they think to read the progress notes for the last 3 months or categorised them according to what they want to review, look at the assessments and see if there is a decline or increase then it does allow critical thinking.'

\subsubsection{The realisation of one benefit often led to further benefits}

The examples that shed light on this benefit are as follows: staff's ability to enter data quickly enabled them to record data immediately rather than at the end of a shift. This led to quicker and better care decisions based on more timely and complete information. Managers realised the benefits of reduced administrative load as they spent time at the start of a shift to review and audit EHRs to gain an accurate picture of what was going on in the facility. This enabled them to provide more specific, accurate directives to the whole care team.

\section{Discussion}

The results suggest that the care staff members had positive attitude towards the introduction of two aged care EHR systems in three organisations. They thought that the system had helped to improve the quality 
of resident records, the fundamental communication system in RACFs. The present research provides insights into the actual benefits of the EHR systems and the way the benefits were achieved. Up until now there has been little in-depth, systematic analysis of the benefits of the use of EHR systems in residential aged care sector, therefore our study helps to fill this knowledge gap.

While in previous studies people showed some positive attitudes towards the quality of the EHR systems and their implementation, in this study most of the care staff members interviewed held such positive attitudes because of the benefits which they perceived. The following is a comparison of the benefits of EHR systems identified in this study with the benefits of other ICT solutions in aged care settings.

\subsection{The benefits to the aged care staff}

Most benefits identified by previous studies were also perceived by various care staff members in this study. These include: easy access to data in every computer at any time the care staff member wants, as also found in the previous studies [10-13]. Moreover, as in three previous studies [10,11,15], quick data retrieval was noticed by different levels of care staff. Consistent with the findings by Munyisia et al. [10] from a questionnaire survey at one of the facilities participating in this study, the ease of both learning and using the system was noticed even by staff who had limited computer skills to start with. The documentation burden on care staff members was reduced after the implementation of aged care EHR systems and this was similar to the findings by Irvine and Kroeger [16].

In addition to the benefits of retrieval, for the first time, this study detailed care staff members' perspectives about the benefits of EHR systems to staff members in aged care: improving the convenience and efficiency of essential health data processing including data entry, storage and distribution. Staff members were empowered by the aged care EHR system because it enabled them to acquire holistic pictures of the residents they were caring for. They preferred entering records in computer rather than writing on paper because they were motivated by the thought that in this way they would be able to influence the care decision making by other staff members because the legible electronic records were more likely to be read.

\subsection{The benefits to the residents}

Urquhart et al. [41], cited in Oroviogoicoechea et al.'s review [43], suggested quality of health care is directly related to the quality of information available to healthcare workers thus information 
management is an essential part of health care delivery. The interviewees' documentation time was perceived to be reduced, allowing staff to spend more time with residents, it is the same as Chau and Turner's finding [14]. The aged care EHR system was perceived to enable care staff members to observe and prevent incidents of undesirable behaviour by residents, a finding which was similar to the findings regarding fall reduction [24]. Hence, EHR systems could facilitate the improvement of outcomes of aged care services if the systems were properly designed and used, as found by Munyisia et al. etc. [10,17,19]. Some care staff members perceived that because of the reduced time needed for documentation, they could focus their efforts on understanding the needs of residents and delivering more resident-centred care. Because of easy accessibility to residents’ information in legible form, some care staff members believed that the system has helped them to develop better care plans and they could follow up with the identified needs, make care decisions faster and respond the care needs quickly.

The up-to-date information was felt to enable staff to understand what had happened to a resident and why. The high quality of information enabled them to think instead of simply following the routine workflow as they might do when using a paper-based record system. The continuous use of the system had enabled staff members to better understand the holistic nature of care service delivery. This had facilitated them to access the care outcomes and continuously improve the quality of care.

\subsection{The benefits to the RACFs}

The benefits of EHRs as perceived by the care staff members were that they were legible [10,11], accurate $[10,20]$, complete $[10,21]$ and concise $[10]$ recording. There were fewer mistakes in EHRs as it was easier to change data on computer than on paper before the data was saved. Despite the desire of management, however, documentation at point-of-care was not found in this study, although it was the most important advantage in Chau and Turner's study [14]. This may be attributed to the personal nature of hands-on aged care services making it difficult for a care staff member to enter data into any sizeable device.

Frequent audits were facilitated by the ease of access to the records $[17,20]$. By providing an easily available channel for all users to share and exchange accurate and high quality information, both internal $[10,23]$ and external $[17,22]$ communication was improved. It had been noted that ICT solutions offered 
the opportunity or had the potential to reduce cost $[16,24]$. Another opportunity to reduce costs is that the need for a continually expanding storage space for paper files is eliminated.

The authorised personnel in the aged care organisations were enabled to customise the EHR systems to fit the organisations' information needs and work practice. Staff was motivated to put more effort into recording since they were encouraged by the thought that their records would be read by their peers and managers. This was valuable to both current staff as well as nursing students and the educational benefits were shared by the whole organisation.

The system helped managers to monitor the information, staff performance and the quality of care delivered. The communication between the staff members and residents was improved by the empathetic manner a staff member displayed in a conversation deriving from the staff members’ improved knowledge about a resident gained from quick data retrieval. Because the evidence was readily available, the systems also improved the aged care facilities' ability to access funding.

Our research findings provide support for investment in aged care EHR systems and in the way staff should use them. A functional and easy to use EHR system is the key factor for realising these benefits. It is also important to encourage the care staff members at all levels of the organisation to keep using the system because the more they use it and input data into it, the greater the benefits of the system. Finally, the heavy burden of documentation in nurses and carers' daily work must be acknowledged [33,44]. Martin [45] finds that care workers gain better satisfaction by spending more time with the older people they looked after than documenting records. With reduced documentation time, it is logical to expect a more satisfied workforce, thus better retention rate in the workforce. Therefore, the EHR systems would contribute to relieving the pressure on the studied RACFs brought about by the workforce shortage.

\subsection{Limitation of the study}

One limitation of our study is that the findings were drawn from interview data with subjective perceptions of the interviewees. This, like all subjective data, would have been influenced by the experience of the individual participants. The other limitation is the representativeness of the different groups of interviewees. There are different perceptions about received benefits between care workers, nurses and management differentiated by their points of view and job roles, and this has not yet been 
analysed, given the limited space for this article. Further research is needed to identify the different perceptions of various levels of staff.

\section{Conclusion}

Increasing numbers of RACFs in Australia and worldwide are introducing EHR systems, however the actual benefits of such investment is yet to be validated and examined in perspective. This study provides evidence to suggest that good quality aged care EHR systems do bring substantial benefits to staff, residents, RACFs and to the residential aged care sector as a whole. They also reduce the burden of documentation on staff. With jobs being made easier and less burdensome, it is logical to conclude that a better staff retention rate could be expected. This would contribute to relieving the pressure on the Australian aged care system brought about by the workforce shortage. The benefits were derived from the nature of the EHR systems compared to paper-based records, the aged care staff members' continuous utilisation of the system and the fact that the realisation of one benefit often led to the realisation of further benefits.

\section{Authors' contributions}

YZ analysed the data and drafted the manuscript; PY designed the study, conducted all the interviews, participated in data analysis, guided and revised the manuscript; JS revised the manuscript. All authors read and approved the final manuscript.

\section{Acknowledgements}

The authors wish to thank the management and care staff members in the aged care organisations who participated in the interview process. They are RSL Care, UnitingCare Ageing South Eastern Region and Warrigal Care. The authors would also like to acknowledge Dr Madeleine Cincotta for her role as copy editor and language consultant and for her contribution to discussion about data analysis. The research was funded by an Industry Linkage Grant of the Australian Research Council (ARC) and four aged care organisations, including Illawarra Retirement Trust and the aforementioned three organisations. The views and conclusions are those of the authors and do not necessarily represent those of the ARC or the University of Wollongong.

\section{Conflicts of interest}

The authors have no financial interest to this work. 


\section{Summary points}

\section{What was known before the study?}

- Information and communication technology (ICT) solutions are going to be increasingly adopted in aged care. They were expected to improve the quality and efficiency of aged care services and reduce care staff work burden.

- The literature showed a number of identified benefits of these ICT solutions, including ease of access, improved efficiency, improved quality of care, improved quality of information, facilitation of management and communication, cost savings and other benefits.

- Electronic health records have the potential to bring benefits to the aged care sector.

\section{What this study has added to the body of knowledge?}

- $\quad$ Aged care EHR systems improved the convenience and efficiency of essential health data processing and empowered aged care staff members. The benefits of EHR to improve aged care outcomes were analysed in detail. Information management, care quality control and access to funding were facilitated by use of the system.

- The ease of use and usefulness of the aged care EHR systems and the way the system was utilised were the factors that contributed to the realisation of the benefits.

- Aged care EHR systems can reduce the documentation burden on care staff members. It is logical to expect the system would contribute to relieving the pressure of the workforce shortage on the Australian aged care sector. 


\section{References}

[1] Secure and Sustainable Pension Reform: Age Pension Age, 2009, available at: http://www.treasurer.gov.au/DisplayDocs.aspx?doc=pressreleases/2009/056.htm\&pageID=\&mi n=wms\&Year=\&DocType=0, accessed September 7, 2011.

[2] Australian Goverment Department of Health and Ageing 2010. 2009-10 Department of Health and Ageing Annual Report, available at:

http://www.health.gov.au/internet/annrpt/publishing.nsf/Content/annual-report-0910toc/\$File/Full\%20Report\%20of\%20the\%202009_10\%20Annual\%20Report.pdf, accessed September 7, 2011.

[3] Australian Goverment Productivity Commission 2011. Caring for Older Australians Productivity Commission Inquiry Report available at: http://www.pc.gov.au/_data/assets/pdf_file/0014/110930/aged-care-volume2.pdf, accessed September 7, 2011.

[4] Australian Institute of Health and Welfare 2010. Australia's health 2010: The twelfth biennial health report of the Australian Institute of Health and Welfare, available at: http://www.aihw.gov.au/WorkArea/DownloadAsset.aspx?id=6442452962\&libID=6442452962, accessed September 7, 2011.

[5] B. Chaudhry, J. Wang, S.Y. Wu, M. Maglione, W. Mojica, E. Roth, S.C. Morton, P.G. Shekelle, Systematic review: Impact of health information technology on quality, efficiency, and costs of medical care, Ann. Intern. Med. 144 (10) (2006) 742-752.

[6] Ageing and Aged Care in Australia, 2008, available at: http://www.health.gov.au/internet/main/publishing.nsf/Content/ageing-publicat-aged-careaustralia.htm ageing-publicat-aged-care-australia-p1 ageing-publicat-aged-care-australia-p1-1, accessed September 7, 2011.

[7] Australian Nursing Federation, 2010. Australian Nursing Federation Annual Report 2009-2010, available at: www.anf.org.au/pdf/reports/annual_report_2010.pdf, accessed September 7, 2011.

[8] S. Koch, M. Hägglund, Health informatics and the delivery of care to older people, Maturitas. 63 (3) (2009) 195-199.

[9] H.E. Resnick, B.B. Manard, R.I. Stone, M. Alwan, Use of Electronic Information Systems in Nursing Homes: United States, 2004, J. Am. Med. Inform. Assn. 16 (2) (2009) 179-186.

[10] E.N. Munyisia, P. Yu, D. Hailey, The changes in caregivers' perceptions about the quality of information and benefits of nursing documentation associated with the introduction of an electronic documentation system in a nursing home, Int. J. Med. Inform. 80 (2) (2011) 116-126.

[11] P. Burns, D.A. Perkins, K. Larsen, A. Dalley, The introduction of electronic medication charts and prescribing in aged care facilities: An evaluation, Australas. J. Ageing. 26 (3) (2007) 131134.

[12] K. Diment, P. Yu, G. Karin, A preliminary investigation of complex adaptive systems as a model for explaining organisational change caused by the introduction of health information systems, eJHI. 6 (1) (2011) e4.

[13] G.L. Alexander, M. Rantz, M. Flesner, M. Diekemper, C. Siem, Clinical Information Systems in Nursing Homes: An Evaluation of Initial Implementation Strategies, CIN. 25 (4) (2007) 189-197

[14] S. Chau, P. Turner, Utilisation of mobile handheld devices for care management at an Australian aged care facility, Electron. Commer. R. A. 5 (4) (2006) 305-312.

[15] D.B. Reuben, Systems approaches to improve quality, performance, and efficiency in the care of older adults, Perm. J. 11 (2) (2007) 48-54.

[16] S.J. Irvine, K. Kroeger, An ICT solution for medical care to residents in residential aged care facilities, Health Inf. Manag. J. 39 (1) (2010) 41-45. 
[17] B.G. Celler, J. Basilakis, M. Budge, N.H. Lovell, Ieee, (Eds.), A clinical monitoring and management system for residential aged care facilitiesed, Ieee, New York, 2006.

[18] D. Shelly, When the Patient Suffers: Optimization of Transitions between Care Facilities, Geriatr. Nurs. 28 (5) (2007) 298-300.

[19] M. Fossum, G.L. Alexander, M. Ehnfors, A. Ehrenberg, Effects of a computerized decision support system on pressure ulcers and malnutrition in nursing homes for the elderly, Int. J. Med. Inform. 80 (9) (2011) 607-617.

[20] J.E. Schnelle, B.M. Bates-Jensen, L. Chu, S.E. Simmons, Accuracy of nursing home medical record information about care-process delivery: Implications for staff management and improvement, J. Am. Geriatr. Soc. 52 (8) (2004) 1378-1383.

[21] S.A. Lindner, J. Ben Davoren, A. Vollmer, B. Williams, C.S. Landefeld, An electronic medical record intervention increased nursing home advance directive orders and documentation, J. Am. Geriatr. Soc. 55 (7) (2007) 1001-1006.

[22] R.S. Dick, E.B. Steen, D.E. Detmer (Eds.), Computer-Based Patient Record: An Essential Technology for Health Care, Revised Edition, 2nd ed, National Academies Press, Washington, DC, USA, 1997.

[23] D. Pierce, G. Fraser, An investigation of medication information transfer and application in aged care facilities in an Australian rural setting, Rural Remote Health. 9 (3) (2009).

[24] C. Bollen, J. Warren, G. Whenan, Introduction of electronic prescribing in an aged care facility, Aust. Fam. Physician. 34 (4) (2005) 283-287.

[25] W.H. Delone, E.R. McLean, The DeLone and McLean Model of Information Systems Success: A Ten-Year Update, J. Manage. Inf. Syst. 19 (4) (2003) 9-30.

[26] G. Paré, L. Lepanto, D. Aubry, C. Sicotte, Toward a multidimensional assessment of picture archiving and communication system success, Int. J. Technol. Assess. 21 (04) (2005) 471-479.

[27] W.-Y. Jen, C.-C. Chao, Measuring mobile patient safety information system success: An empirical study, Int. J. Med. Inform. 77 (10) (2008) 689-697.

[28] K. Häyrinen, K. Saranto, P. Nykänen, Definition, structure, content, use and impacts of electronic health records: A review of the research literature, Int. J. Med. Inform. 77 (5) (2008) 291-304.

[29] J.F. Golob Jr, A.M.A. Fadlalla, J.A. Kan, N.P. Patel, C.J. Yowler, J.A. Claridge, Validation of Surgical Intensive Care-Infection Registry: A Medical Informatics System for Intensive Care Unit Research, Quality of Care Improvement, and Daily Patient Care, J. Am. Coll. Surgeons. 207 (2) (2008) 164-173.

[30] G.O. Otieno, T. Hinako, A. Motohiro, K. Daisuke, N. Keiko, Measuring effectiveness of electronic medical records systems: Towards building a composite index for benchmarking hospitals, Int. J. Med. Inform. 77 (10) (2008) 657-669.

[31] S. Chatterjee, S. Chakraborty, S. Sarker, S. Sarker, F.Y. Lau, Examining the success factors for mobile work in healthcare: A deductive study, Decis. Support Syst. 46 (3) (2009) 620-633.

[32] S. Petter, A. Fruhling, Evaluating the success of an emergency response medical information system, Int. J. Med. Inform. 80 (7) (2011) 480-489.

[33] E.N. Munyisia, P. Yu, D. Hailey, How nursing staff spend their time on activities in a nursing home: an observational study, J. Adv. Nurs. 67 (9) (2011) 1908-1917.

[34] E.N. Munyisia, P. Yu, D. Hailey, Does the introduction of an electronic nursing documentation system in a nursing home reduce time on documentation for the nursing staff?, Int. J. Med. Inform. 80 (11) (2011) 782-792.

[35] N. Lee, I. Lings, (Eds.), Doing business research: a guide to theory and practiceed, SAGE, London, 2008. 
[36] B.G. Glaser, A.L. Strauss, (Eds.), The Discovery of grounded theory: strategies for qualitative researched, Aldine-Atherton, Chicago, 1967.

[37] A.L. Strauss, J.M. Corbin, (Eds.), Basics of qualitative research: techniques and procedures for developing grounded theoryed, Sage Publications, Thousand Oaks, 1998.

[38] H.-F. Hsieh, S.E. Shannon, Three Approaches to Qualitative Content Analysis, Qual. Health Res. 15 (9) (2005) 1277-1288.

[39] U.H. Graneheim, B. Lundman, Qualitative content analysis in nursing research: concepts, procedures and measures to achieve trustworthiness, Nurs. Educ. Today. 24 (2) (2004) 105-112.

[40] J. Barroso, D. Buchanan, P. Tomlinson, G. van Servellen, Social Support and Long-Term Survivors of AIDS, Western J. Nurs. Res. 19 (5) (1997) 554-582.

[41] C. Urquhart, R. Currell, J. Grant Maria, R. Hardiker Nicholas, Nursing record systems: effects on nursing practice and healthcare outcomes, Cochrane Database Syst. Rev. (1) (2003) 12-45.

[42] N. Wang, D. Hailey, P. Yu, Quality of nursing documentation and approaches to its evaluation: a mixed-method systematic review, J. Adv. Nurs. 67 (9) (2011) 1858-1875.

[43] C. Oroviogoicoechea, B. Elliott, R. Watson, Review: evaluating information systems in nursing, J. Clin. Nurs. 17 (5) (2008) 567-575.

[44] A. Martin, C. Hinds, M. Felix, Documentation practices of nurses in long-term care, J. Clin. Nurs. 8 (4) (1999) 345-352.

[45] B. Martin, D. King, et al. (Eds.), Who cares for older Australians? A picture of the residential and community based aged care workforce, 2007ed, Commonwealth of Australia, Barton, A.C.T., 2008. 